\title{
Prevalence and Risk Factors of Domestic Violence against Iranian Women: A Cross-Sectional Study
}

\author{
Fathola Mohamadian', Ataollah Hashemian², Maryam Bagheri ${ }^{3}$, Ashraf Direkvand-Moghadam ${ }^{4, *}$ \\ 'Department of Psychology, Psychosocial Injuries Research Center, Ilam University of Medical Sciences, Ilam, Iran \\ ${ }^{2}$ Department of Criminal Low and Criminology, Psychosocial Injuries Research Center, Ilam University of Medical Sciences, Ilam, Iran \\ ${ }^{3}$ Department of Neuroscience, Psychosocial Injuries Research Center, Ilam University of Medical Sciences, Ilam, Iran \\ ${ }^{4}$ Psychosocial Injuries Research Center, Faculty of Nursing and Midwifery, Ilam University of Medical Sciences, Ilam, Iran
}

Background: Violence against women in families is the most common form of violence against them. The purpose of this study was to determine the prevalence of domestic violence and its effects on married women of Ilam.

Methods: In this descriptive-sectional research, 334 married women referred to medical health centers in Ilam were selected to participate using a random sampling method. After obtaining their consent to participate in the study, participants responded to a 46 items questionnaire and responses were analyzed using IBM SPSS for Windows ver. 20.0 (IBM Co., Armonk, NY, USA).

Results: The majority of the participants reported experiencing domestic violence and emotional violence was more prevalent than other kinds of violence. Logistic regression analysis showed that lower education level, marriage at a younger age, shorter duration of marriage, fewer children, being a housewife, and husband's unemployment had a significant relationship with domestic violence against women.

Conclusion: The high prevalence of wife abuse in Ilam especially emotional violence due to lower education levels and marriage at younger age could be a serious threat for women's health as well as for other members of the family. This could be a grounding factor for other social harms such as suicide and this issue must be studied from legal, religious, and cultural standpoints.

Keywords: Domestic Violence; Emotional Violence; Physical Abuse; Risk Factors of Violence; Sexual Offenses 


\section{INTRODUCTION}

Anger is an emotion that all individuals experience and it is considered a natural aspect of married life. Actually, it seems that the more relationships an individual has, the more opportunities for anger appearance. However, if this emotion is not controlled, it could lead to verbal and physical violence, harm intimate relationships, and finally to marital dissatisfaction and even separation and divorce. ${ }^{1)}$ Studies show that women are subjected to violence 6 times more than men. ${ }^{2)}$

Domestic violence against women occurs in several forms such as physical, emotional, and sexual violence and is an important issue from the human health and rights perspective. ${ }^{3,4)}$ Domestic violence occurs in all countries, irrespective of the social, economic, religious, or cultural differences. ${ }^{2)}$

Although exact statistics are not available for the frequency of domestic violence against women, a previous study indicated that $20 \%$ to $50 \%$ of the women worldwide have experienced some form of domestic violence in their lifetime. ${ }^{5)}$ An Iranian study reported that $20.2 \%$ of Iranian women experienced physical violence at any given point of time. Additionally, the prevalence of psychological, sexual, and any type of violence were $41 \%, 10.9 \%$, and $47.3 \%$, respectively. ${ }^{6}$ )

Previous studies have mentioned age, ${ }^{7)}$ education level, ${ }^{8)}$ occupation, ${ }^{9)}$ family relationships between couples, ${ }^{10)}$ and religious beliefs ${ }^{11}$ as factors influencing domestic violence.

What is certain is that violence against women exists everywhere in the world, leading to adverse effects on their lives and marital relationships. ${ }^{12)}$ Both physical and mental problems are important results of domestic violence. ${ }^{13)}$ Other consequences of domestic violence include injury and death, ${ }^{14)}$ effects on pregnancy outcomes and newborns, ${ }^{15)}$ and women's mental health. ${ }^{16)}$ Women are the most important segments of the society and paying attention to their own health affects their family health. ${ }^{17,18)}$

Ilam is one of the border provinces of Iran and the Ilamian people have experienced severe stress caused by the long years of war. Experiencing such stress may lead to psychological disorders among some people. Because there is a relationship between psychological disorders and the prevalence of violence, evaluating the prevalence of violence in this society is necessary. Considering the physical and psychological consequences of domestic violence against women the present study aimed to determine the prevalence and relative factors of domestic violence against Iranian women.

\section{METHODS}

\section{Study Subjects}

This cross-sectional study's target population included all married women who were referred to medical health centers in Ilam during the research period. The sample size was determined by the Cochran formula and included 334 eligible women. Simple random sampling method was used. Across all age groups, women living in Ilam who were willing to participate in the study, were enrolled to participate in this study. However, all women who reported having mental disorders or using certain medications interfering with the nervous system were excluded from the study. Additionally, we excluded women whose husbands have these problems.

\section{Study Methods}

Data was collected using a 46 items questionnaire which was created by the researchers based on the previous literature and the social and cultural environment of Ilam. Content and construct validity were assessed to determine the questionnaire validity. In the present study, we used factor analysis to determine the construct validity. Exploratory factor analysis was performed using sampling index Kaiser-MeyerOlkin and Cruet-Bartlett's test, principal component analysis, and varimax rotation. Eigen values and scree plot were used to determine the number of factors. A minimum $40 \%$ load requirement was used to extract each factor from the factor analysis. Eigen values more than 2 were considered. Internal consistency reliability was used to determine the questionnaire's reliability (Cronbach's $\alpha=0.854$ ).

All variables including age, education level, occupation, age when married, duration of marriage, number of children, kinship with husband's family, whether they lived with husband's parents, and addiction were recorded by participants. In the current study, variables such as monthly income, monthly expenses, and private accommodation were considered as crucial for assessing the economic situation. Poverty line was determined on the basis of $50 \%$ to $66 \%$ of median household expenditures.

After explaining the purpose of the study, and obtaining informed consent to participate in the study, participants completed the questionnaires. However, questionnaires were completed by trained researchers for participants who were illiterate.

\section{Statistics}

After data collection, descriptive statistics, chi-square test, and Fisher's test were conducted via IBM SPSS for Windows ver. 20.0 (IBM Co., Armonk, NY, USA). In order to remove the effects of the confounding variables, Logistic regression was used.

\section{RESULTS}

\section{General Characteristics of the Participants}

Descriptive results of this research study showed that women aged 2029 years (44\%) responded to the survey most frequently. About, $72 \%$ of the participants had a relationship with their husband's family but only $28 \%$ were living with their husband's parents. Overall, $82.6 \%$ of the participants considered their husband as ethical and only $2 \%$ reported that their husbands were addicted. Demographic characteristics and other factors related to the violence against women in Ilam are presented in Table 1.

\section{Risk for Domestic Violence against Women}

In the present study, exploratory factor analysis identified three di- 
Table 1. Demographic characteristics and other factors related to the violence against women in llam

\begin{tabular}{|c|c|c|c|c|}
\hline \multirow{2}{*}{ Characteristic } & \multicolumn{2}{|c|}{ Group* } & \multirow{2}{*}{ Total } & \multirow{2}{*}{ P-value ${ }^{\dagger}$} \\
\hline & Yes & No & & \\
\hline Total & $206(62)$ & $128(38)$ & 334 & \\
\hline Age $(y)$ & & & & 0.1 \\
\hline $15-19$ & $12(80)$ & $3(20)$ & 15 & \\
\hline 20-29 & $80(54)$ & $67(46)$ & 147 & \\
\hline 30-39 & $79(68)$ & 37 (32) & 116 & \\
\hline $40-49$ & $30(66.6)$ & $105(33.3)$ & 45 & \\
\hline$\geq 50$ & $5(45)$ & $6(55)$ & 11 & \\
\hline Education level & & & & 0.01 \\
\hline Illiterate & $14(70)$ & $6(30)$ & 20 & \\
\hline Below diploma & 72 (76.6) & $22(23.4)$ & 94 & \\
\hline Diploma & 78 (59.5) & $53(40.5)$ & 131 & \\
\hline Associate's degree & $23(51.1)$ & $22(48.9)$ & 45 & \\
\hline Bachelor's degree & $16(42.1)$ & $22(47.9)$ & 38 & \\
\hline Master's degree & $3(50)$ & $3(50)$ & 6 & \\
\hline Marriage age (y) & & & & 0.000 \\
\hline$<15$ & $19(76)$ & $6(24)$ & 25 & \\
\hline $15-19$ & $95(74)$ & $33(26)$ & 128 & \\
\hline $20-24$ & $73(55)$ & $59(45)$ & 132 & \\
\hline $25-29$ & $15(41)$ & $22(59)$ & 37 & \\
\hline$\geq 30$ & $5(42)$ & $7(58)$ & 12 & \\
\hline Marriage duration (y) & & & & 0.03 \\
\hline$\leq 5$ & $68(52)$ & $63(48)$ & 131 & \\
\hline $6-10$ & $53(64)$ & $30(36)$ & 83 & \\
\hline $11-15$ & $37(67)$ & $18(33)$ & 55 & \\
\hline $16-20$ & $24(80)$ & $6(20)$ & 30 & \\
\hline $20-30$ & $19(76)$ & $6(24)$ & 25 & \\
\hline$>30$ & $5(50)$ & $5(50)$ & 10 & \\
\hline No. of children & & & & 0.05 \\
\hline None & 21 (41) & $30(59)$ & 51 & \\
\hline $1-3$ & 143 (62) & $87(38)$ & 230 & \\
\hline $4-7$ & 34 (79) & $9(21)$ & 43 & \\
\hline$>7$ & $8(80)$ & $2(20)$ & 10 & \\
\hline Occupation & & & & 0.02 \\
\hline Government job & $41(48)$ & $44(52)$ & 85 & \\
\hline Housewife & $159(66)$ & $82(34)$ & 241 & \\
\hline Collegian & $7(86)$ & $1(14)$ & 8 & \\
\hline Husband's education level & & & & 0.000 \\
\hline Illiterate & $11(73)$ & $4(27)$ & 15 & \\
\hline Below diploma & 63 (79.7) & $16(20.3)$ & 79 & \\
\hline Diploma & $76(61.8)$ & $43(38.2)$ & 118 & \\
\hline Associate's degree & $22(62.8)$ & 13 (37.2) & 35 & \\
\hline Bachelor's degree & 27 (42.1) & 37 (57.9) & 64 & \\
\hline Master's degree & $7(30.4)$ & $16(69.6)$ & 23 & \\
\hline Husband occupation & & & & 0.08 \\
\hline Government job & $140(58)$ & $102(42)$ & 242 & \\
\hline Retired & $9(60)$ & $6(40)$ & 15 & \\
\hline Unemployed & $26(76)$ & $9(24)$ & 35 & \\
\hline Nongovernment job & $31(74)$ & $11(26)$ & 42 & \\
\hline Kinship with the husband's family & & & & 0.04 \\
\hline Yes & 83 (59.2) & $57(40.8)$ & 140 & \\
\hline No & $123(63.4)$ & $71(36.6)$ & 194 & \\
\hline Living with husband's parents & & & & 0.1 \\
\hline Yes & $63(67)$ & $31(33)$ & 94 & \\
\hline No & $143(59.5)$ & $95(40.5)$ & 240 & \\
\hline Husband's addiction & & & & 0.1 \\
\hline Yes & $4(58)$ & $3(42)$ & 7 & \\
\hline No & $185(61)$ & $122(39)$ & 307 & \\
\hline Not known & $12(86)$ & $2(14)$ & 14 & \\
\hline No answer & $5(84)$ & $1(16)$ & 6 & \\
\hline Economic situation & & & & 0.1 \\
\hline Above the poverty line & $100(48.3)$ & $66(51.5)$ & 166 & \\
\hline Below the poverty line & $106(51.7)$ & $62(48.5)$ & 168 & \\
\hline
\end{tabular}

Values are presented as number (\%).

${ }^{*}$ History of domestic violence against women. ${ }^{\dagger}$ Calculated by chi-square test. 
mensions of violence against women physical, emotional, and sexual from our 46 items questionnaire. Overall, $62 \%$ of the participants reported being violated by their husbands. More specifically, $33.8 \%$ of the participants were physically violated, $54.2 \%$ were emotionally violated, and $23.7 \%$ (79/334) were sexually violated. Based on our results there was no significant relationship between economic situation and domestic violence against women $(\mathrm{P}=0.1)$. The logistic regression analysis showed that lower education level, marriage at younger age, shorter duration of marriage, fewer children, being a housewife, and husband's unemployment have a significant relationship with domestic violence against women $(\mathrm{P}<0.05)$ (Table 2$)$.

\section{DISCUSSION}

The present study investigated the prevalence and relative factors of domestic violence against Iranian women. Of every ten women who participated in this research study, 6 reported being abused by their husbands. This frequency is higher than the results of a previous study that claimed violence prevalence up to $50 \%{ }^{5}{ }^{5}$ However, another study reported that $75.9 \%$ of their study population was physically, psychologically, and sexually abused by their husbands. ${ }^{13)}$ The researchers believe that in some Iranian families, cultural and social issues have created conditions that men have a powerful position while women have a weak position in their family structure. Therefore, in such families women are vulnerable and fragile. In addition to the difference between the prevalence of violence against women in Iranian and international studies, differences exist in the reported prevalence even among Iranian studies. The prevalence reported in this study was higher than other Iranian studies ${ }^{19,20)}$ that showed that all types of violence against women ranged from $20 \%$ to $43 \%{ }^{20)}$

Our results show that emotional violence had the highest prevalence; however, sexual violence had the lowest prevalence among our

Table 2. Association between domestic violence against women and other variables using logistic regression analysis

\begin{tabular}{|c|c|c|c|c|}
\hline Characteristic & $\mathrm{OR}(95 \% \mathrm{Cl})$ & P-value* & Adjusted $\mathrm{OR}^{\dagger}(95 \% \mathrm{Cl})$ & P-value \\
\hline Education level & & 0.002 & & 0.04 \\
\hline Master's degree & 1 (reference) & & 1 (reference) & \\
\hline Bachelor's degree & $1.001(1-1.001)$ & & $1.2(1-1.7)$ & \\
\hline Associate's degree & $1.81(0.61-5.35)$ & & $1.81(0.61-5.35)$ & \\
\hline Diploma & $1.6(0.65-3)$ & & $1.9(0.9-3.2)$ & \\
\hline Under diploma & $2(1-2.9)$ & & $2.4(1-4.2)$ & \\
\hline Illiterate & $3.1(1.8-5.1)$ & & $4.2(2.1-6.8)$ & \\
\hline Marriage age (y) & & 0.01 & & 0.001 \\
\hline$\geq 30$ & 1 (reference) & & 1 (reference) & \\
\hline $25-29$ & $1.9(0.31-4.15)$ & & $1.7(0.7-3.67)$ & \\
\hline $20-24$ & $1.1(0.260-4.7)$ & & $1.4(0.5-2.3)$ & \\
\hline $15-19$ & $1.43(0.58-4.93)$ & & 1.5 (0.8-3.02) & \\
\hline$<15$ & $3.98(1.15-11.5)$ & & $5.05(2.2-10.7)$ & \\
\hline Marriage duration (y) & & 0.115 & & 0.000 \\
\hline$>30$ & 1.0 (reference) & & 1.0 (reference) & \\
\hline $20-30$ & $0.65(0.48-0.79)$ & & $0.67(0.51-0.87)$ & \\
\hline $16-20$ & $0.72(0.45-1.1)$ & & $0.9(0.7-1.2)$ & \\
\hline $11-15$ & $1.47(0.89-2.2)$ & & $1.5(0.96-2.34)$ & \\
\hline $6-10$ & $2.13(1.45-2.98)$ & & $2.5(1.7-4.1)$ & \\
\hline$\leq 5$ & $5.1(2.87-9)$ & & $6.3(3.1-10.2)$ & \\
\hline No. of children & & 0.003 & & 0.000 \\
\hline$>7$ & 1.0 (reference) & & 1.0 (reference) & \\
\hline $4-7$ & $1.4(0.94-2.28)$ & & $1.8(1.1-3.2)$ & \\
\hline $1-3$ & $1.03(1.01-1.06)$ & & $1.4(1-2.6)$ & \\
\hline None & $1.39(1-1.87)$ & & $1.9(1.7-4.1)$ & \\
\hline Occupation & & 0.001 & & 0.02 \\
\hline Government job & 1.0 (reference) & & 1.0 (reference) & \\
\hline Housewife & $2(2-2.01)$ & & $2.7(2.5-3)$ & \\
\hline Collegian & $0.73(0.54-0.97)$ & & $0.74(0.55-0.99)$ & \\
\hline Husband occupation & & 0.04 & & 0.000 \\
\hline Government job & 1.0 (reference) & & 1.0 (reference) & \\
\hline Retired & $1.4(0.93-2.2)$ & & $2.5(2.01-3)$ & \\
\hline Unemployed & $5.11(2.91-9.07)$ & & $5.19(2.96-9.11)$ & \\
\hline Nongovernment job & $2.18(1.53-3.1)$ & & $2.9(1.8-3.22)$ & \\
\hline
\end{tabular}

$\mathrm{OR}$, odds ratio; $\mathrm{Cl}$, confidence interval.

${ }^{*}$ Calculated by univariate logistic regression analysis. ${ }^{\dagger}$ Adjusting for age, education, occupation, marriage age, marriage duration, number of children, and husband's occupation as confounding factors. ${ }^{\ddagger}$ Calculated by multivariate logistic regression analysis. 
study population. In another study, $37 \%$ of the women reported the psychological violence, while $14 \%$ reported physical and sexual violence in their homes. ${ }^{21)}$

In traditional societies where men are considered superior to women and are responsible for the family life, there is a higher level of sexual violence against women. ${ }^{22)}$ While, in societies where men consider women as their equals have lower rates of sexual violence against women. ${ }^{23)}$

We found a statistically meaningful relationship between education level and occupation with respect to violence against women. The results of univariate logistic regression showed that the risk of violence against women was 3.1 times higher among illiterate women as compared to women with a master's degree education and the multivariate logistic regression indicated that risk of violence was 4.2 times higher. Additionally, multivariate logistic regression indicated that the risk of violence against women was 2.7 times higher among housewives compared to women who had government jobs.

Our results concur with Bolheri and Qhahary ${ }^{3)}$ who considered unemployment, having low levels of education, and low income as main effective factors of domestic violence against women. In line with our results, an Indian study reported a statistically meaningful relationship between education level and occupation with violence against women. ${ }^{21)}$ We did not find ant studies that yielded different results.

We found a statistically meaningful relationship between age when married, and duration of marriage with violence against women. In line with our results, an Indian study reported a statistically meaningful relationship between duration of marriage and violence against women. ${ }^{21)}$

Based on the results of our in multivariate logistic regression analysis, there is a statistically significant relationship between the number of children and violence against women. Specifically, the possibility of violence against women who did not have children was 1.9 times more than women who had more than 7 children.

A previous study has linked the number of living male children and domestic violence against women. ${ }^{24)}$ Similar to our results, previous studies confirmed that higher the number of children is associated whit higher the violence against women. ${ }^{25,26)}$

Our results demonstrated that the kinship with husband's family is a risk factor for domestic violence against women. Another study in line with our results, confirmed the relationship between, living with the extended family and domestic violence against women. ${ }^{24)}$

Based the results of our multivariate logistic regression analysis, getting married early was a risk factor for domestic violence against women. Thus, the risk of violence against women was 5 times higher among women who were married when they were younger than 15 years than women who had married when they were older than 30 years. Possibly, the inability of young women to perform their duties and lack of communication skills leads to higher risk of domestic violence against young women. Other studies have also confirmed our results. ${ }^{26,27)}$

The results of the present study showed that shorter duration of marriage is a risk factor for violence against women. Univariate logistic regression analysis indicated that the possibility of violence against women who had been married for less than 5 years was 5 times more than women who had been married for more than 30 years. This risk was 6.3 times using multivariate logistic regression analysis. In some Iranian families, marriages are still arranged traditionally. Hence, in such a marriage, a couple may not know each other very well. Therefore, an insufficient knowledge can led to high risk of violence against women in the early years of marriage. Recently a study in line with our results has confirmed the association between length of marriage and the risk of violence against women. ${ }^{28)}$

Probably the men who have been abused in childhood are more likely than other men to commit violence against women. ${ }^{29)}$ In the current study, data were not available about the husband's childhood history for women who were subjected to violence by their husbands. This is a limitation of the current study.

We could say that the high prevalence of wife abuse in Ilam especially emotional violence due to lower education levels and marriage at younger age could be a serious threat for women's health as well as for other members of the family. This could be a grounding factor for other social harms such as suicide and this issue must be studied from legal, religious, and cultural standpoints.

\section{CONFLICT OF INTEREST}

No potential conflict of interest relevant to this article was reported.

\section{ACKNOWLEDGMENTS}

This study was approved by the Ilam University of Medical Sciences. We thank the coordinators and data collectors who assisted in this study.

\section{REFERENCES}

1. Wallace H. Characteristics of family violence. In: Wallace, $\mathrm{H}$, editor. Family violence: legal, medical, and social perspectives. Boston (MA): Pearson; 2005.

2. Watts C, Zimmerman C. Violence against women: global scope and magnitude. Lancet 2002;359:1232-7.

3. Bolhari J, Qhahary S. Life Skills for violated women. Tehran: Danzheh; 2008.

4. Macy RJ, Renz C, Pelino E. Partner violence and substance abuse are intertwined: women's perceptions of violence-substance connections. Violence Against Women 2013;19:881-902.

5. World Health Organization. World report on violence and health. Geneva: World Health Organization; 2002.

6. Nouhjah S, Latifi SM, Haghighi M, Eatesam H, Fatholahifar A, Zaman $\mathrm{N}$, et al. Prevalence of domestic violence and its related factors in women referred to health centers in Khuzestan Province. Behbood J 2011;15:278-86.

7. Afifi M. Wealth Index association with gender issues and the repro- 
ductive health of Egyptian women. Nurs Health Sci 2009;11:29-36.

8. Faramarzi M, Esmailzadeh S, Mosavi S. Prevalence and determinants of intimate partner violence in Babol City, Islamic Republic of Iran. East Mediterr Health J 2005;11:870-9.

9. Akmatov MK, Mikolajczyk RT, Labeeb S, Dhaher E, Khan MM. Factors associated with wife beating in Egypt: analysis of two surveys (1995 and 2005). BMC Womens Health 2008;8:15.

10. Naeem F, Irfan M, Zaidi QA, Kingdon D, Ayub M. Angry wives, abusive husbands: relationship between domestic violence and psychosocial variables. Womens Health Issues 2008;18:453-62.

11. Tashkandi A, Rasheed FP. Wife abuse: a hidden problem: a study among Saudi women attending PHC centres. East Mediterr Health J 2009;15:1242-53.

12. Babu BV, Kar SK. Domestic violence against women in eastern India: a population-based study on prevalence and related issues. BMC Public Health 2009;9:129.

13. Avdibegovic E, Sinanovic O. Consequences of domestic violence on women's mental health in Bosnia and Herzegovina. Croat Med J 2006;47:730-41.

14. Forjuoh SN, Zwi AB. Violence against children and adolescents: international perspectives. Pediatr Clin North Am 1998;45:415-26.

15. Martin SL, Mackie L, Kupper LL, Buescher PA, Moracco KE. Physical abuse of women before, during, and after pregnancy. JAMA 2001;285: 1581-4.

16. Campbell JC. Health consequences of intimate partner violence. Lancet 2002;359:1331-6.

17. Direkvand-Moghadam A, Khosravi A. Effect of acupressure on postoperative nausea and vomiting in cesarean section: a randomised controlled trial. J Clin Diagn Res 2013;7:2247-9.

18. Direkvand-Moghadam A, Kaikhavani S, Sayehmiri K. The worldwide prevalence of premenstrual syndrome: a systematic review and metaanalysis study. Iran J Obstet Gynecol Infertil 2013;16:8-17.

19. Mousavian S, Es'haghian A. Evaluation of spouse abuse in married women. J Forensic Med 2001;2:41-8.

20. Nojomi M, Agaee S, Eslami S. Domestic violence against women attending gynecologic outpatient clinics. Arch Iran Med 2007;10:309-15.

21. Mahapatro M, Gupta R, Gupta V. The risk factor of domestic violence in India. Indian J Community Med 2012;37:153-7.

22. Turchik JA, Probst DR, Chau M, Nigoff A, Gidycz CA. Factors predicting the type of tactics used to resist sexual assault: a prospective study of college women. J Consult Clin Psychol 2007;75:605-14.

23. Catalano SM. Intimate partner violence, 1993-2010 [Internet]. Washington (DC): Bureau of Justice Statistics; 2012 [cited 2013 May 18]. Available from: http://bjs.ojp.usdoj.gov/index.cfm?ty=pbdetail\&iid= 4536.

24. Martin SL, Tsui AO, Maitra K, Marinshaw R. Domestic violence in northern India. Am J Epidemiol 1999;150:417-26.

25. Ghazizadeh A. Domestic violence: a cross-sectional study in an Iranian city. East Mediterr Health J 2005;11:880-7.

26. Yount KM, Li L. Domestic violence against married women in Egypt. Sex Roles 2010;63:332-47.

27. Mohammadhosseini E, Sahraean L, Bahrami T. Domestic abuse before, during and after pregnancy in Jahrom, Islamic Republic of Iran. East Mediterr Health J 2010;16:752-8.

28. Kargar Jahromi M, Jamali S, Rahmanian Koshkaki A, Javadpour S. Prevalence and risk factors of domestic violence against women by their husbands in Iran. Glob J Health Sci 2015;8:175-83.

29. Vezina J, Hebert M. Risk factors for victimization in romantic relationships of young women: a review of empirical studies and implications for prevention. Trauma Violence Abuse 2007;8:33-66. 